PERSPECTIVA TEOLÓGICA ADERE A UMA LICENÇA CREATIVE COMMONS ATRIBUIÇÃO 4.0 INTERNACIONAL - (CC BY 4.0)

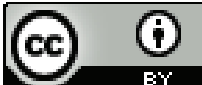

DOI: $10.20911 / 21768757 v 53 n 1 p 17 / 2021$

ARTIGOS / ARTICLES

\title{
AMORIS LAETITIA: UM "SIM" RADICAL À PASTORALIDADE DA TEOLOGIA MORAL
}

Amoris Laetitia: a Radical "Yes" to the Pastorality of Moral Theology

Ronaldo Zacharias *

RESUMO: O presente artigo evidencia o núcleo do conflito que tem polarizado as discussões sobre a Amoris Laetitia na Igreja. Depois de referir-se à centralidade do sujeito no processo de decisão moral e à necessidade de integrar as dimensões subjetiva e objetiva da moralidade, apresenta algumas ambiguidades herdadas da tradição sobre matrimônio e sexualidade a serem reconsideradas. Propõe que essa tarefa seja feita à luz tanto da primazia dada pelo Papa Francisco ao amor e à misericórdia em relação à objetividade das normas quanto da prioridade concedida por ele à pastoral como critério hermenêutico na reflexão moral.

PALAVRAS-CHAVE: Amoris Laetitia. Magistério pastoral. Divorciados recasados. Discernimento seletivo. Misericórdia inclusiva.

ABSTRACT: This article underlines the conflict at the core of the Church's discussions about Amoris Laetitia. After exploring the centrality of the subject in the moral decision-making process and the need to integrate both the objective and subjective dimensions of morality, it presents certain ambiguities, inherited from the tradition, regarding matrimony and sexuality that are worth reconsidering. It also suggests that such a task be done in the light of the precedence Pope Francis has given to love and mercy, specifically regarding the objectivity of norms, as well as of his priority for pastoral practice, as a hermeneutical criterion for a moral reflection.

KEYWORDS: Amoris Laetitia. Pastoral Teaching. Divorced Remarried. Selective Discernment. Inclusive Mercy.

* Centro Universitário Salesiano de São Paulo, Americana, São Paulo, Brasil. 


\section{Introdução}

G mbora a Exortação Apostólica Pós-Sinodal Amoris Laetitia (FRANCISECO, 2016a; daqui em diante $=\mathrm{AL}$ ) tenha sido resultado de um longo processo sinodal, a sua publicação suscitou inúmeras e pesadas críticas e um movimento de rejeição em ambientes católicos. Ela foi acusada de abordar temas morais considerados indiscutíveis, apesar de Francisco deixar claro que até mesmo sobre questões doutrinais pode haver, sim, ulteriores aprofundamentos e desenvolvimentos (KASPER, 2014, p. 10). ${ }^{1}$

E, nesse cenário, Francisco se encontra com vozes que o acusam de semear confusão e ambiguidade e, portanto, dividir a Igreja, desorientar os fiéis e conduzi-los à infidelidade. ${ }^{2}$ Parece estar em jogo - por mais retas que sejam as intenções - o controle da ação do Espírito Santo, como se Ele não pudesse suscitar uma compreensão mais profunda da verdade, mesmo se isso levasse a Igreja a ter de rever a sua doutrina. Negar que a AL não representa apenas a voz de Francisco, mas o parecer da maioria do episcopado representado nas Assembleias sinodais - visto que Francisco "respeitou o resultado das votações, não indo além dele nem ficando um milímetro sequer atrás dele" (KASPER, 2019, p. 20) -, significa rejeitar um "processo de discernimento", como é a sinodalidade. Francisco tem plena convicção de que "o caminho da sinodalidade é precisamente o caminho que Deus espera da Igreja do terceiro milênio" (FRANCISCO, 2015).

Na reflexão que segue, escolhi como método tomar parte diretamente na discussão do problema, abordando alguns dos seus elementos centrais e indicando algumas pistas para que ele possa ser superado. Acredito evidenciar, desse modo, que o ensinamento de Francisco não apenas possui uma profunda índole pastoral, mas pode-nos ajudar a assumir a pastoral como critério no juízo moral.

\section{A prioridade do sujeito moral em relação ao objeto da moral}

Dos 9 capítulos, 325 parágrafos e 390 notas de rodapé da Exortação, foi um capítulo, com um dos seus parágrafos e uma das suas notas de rodapé, que

\footnotetext{
${ }^{1}$ Para Gerald O'Collins, a AL “é uma história não apenas de continuidade básica, mas de significativo desenvolvimento no tema abordado, nas conclusões a que chegou e nas fontes em que se inspirou" (2016, p. 906).

${ }^{2}$ Basta ter presente, por exemplo, a carta "Criar clareza. Alguns nós por resolver em 'Amoris Laetitia - Um apelo", que os cardeais Carlo Caffarra, Joachim Meisner, Raymond Burke e Walter Brandmüller dirigiram ao Papa Francisco pedindo a ele que dirimisse as incertezas e criasse clareza em relação ao Capítulo VIII da Exortação Apostólica Pós-Sinodal Amoris Laetitia. Disponível em: http://chiesa.espresso.repubblica.it/articolo/1351410.html?refresh_ce. Acesso em: 04 nov. 2020.
} 
quase provocaram um cisma na Igreja. ${ }^{3} \mathrm{O}$ capítulo é o oitavo - Acompanhar, discernir e integrar a fragilidade; o parágrafo e a nota são os que seguem:

Por isso, um pastor não pode sentir-se satisfeito apenas aplicando leis morais aos que vivem em situações "irregulares", como se fossem pedras que se atiram contra a vida das pessoas. É o caso dos corações fechados, que muitas vezes se escondem atrás dos ensinamentos da Igreja "para se sentar na cátedra de Moisés e julgar, às vezes com superioridade e superficialidade, os casos difíceis e as famílias feridas". Na mesma linha se pronunciou a Comissão Teológica Internacional: "A lei natural não pode ser apresentada como um conjunto já constituído de regras que se impõem a priori ao sujeito moral, mas é uma fonte de inspiração objetiva para o seu processo, eminentemente pessoal, de tomada de decisão". Por causa dos condicionalismos ou dos fatores atenuantes, é possível que uma pessoa, no meio de uma situação objetiva de pecado - mas subjetivamente não seja culpada ou não o seja plenamente - possa viver em graça de Deus, possa amar e possa também crescer na vida de graça e de caridade, recebendo para isso a ajuda da Igreja. O discernimento deve ajudar a encontrar os caminhos possíveis de resposta a Deus e de crescimento no meio dos limites. Por pensar que tudo seja preto ou branco, às vezes fechamos o caminho da graça e do crescimento e desencorajamos percursos de santificação que dão glória a Deus (AL, n. 305). ${ }^{4}$

Em certos casos, poderia haver também a ajuda dos sacramentos. Por isso, "aos sacerdotes, lembro que o confessionário não deve ser uma câmara de tortura, mas o lugar da misericórdia do Senhor" (EG, n. 44). E de igual modo assinalo que a Eucaristia "não é um prêmio para os perfeitos, mas um remédio generoso e um alimento para os fracos" (EG, n. 47). (AL 305, nota n. 41).

Mesmo atendo-me mais especificamente ao Cap. VIII e considerando a real possibilidade de interpretações indevidas que dele possam ser feitas, terei presente a recomendação feita por José Tomás Alvarado Marambio, de que, na leitura crítica de um texto, deve-se sempre respeitar uma regra hermenêutica básica: o texto deve ser considerado no seu contexto e não de forma isolada (ALVARADO MARAMBIO, 2016, p. 391-394).

O que Francisco propõe é repensar a questão moral à luz do modo pastoral de se aproximar dos casais em situações ditas "irregulares". Em momento algum Francisco pôs em cheque a doutrina da Igreja. Ele simplesmente considera que, mesmo num contexto chamado "irregular", as pessoas podem viver um amor esponsal, com tudo o que ele implica de doação, cuidado, fidelidade, abertura, reciprocidade, verdade, serviço. Em outras palavras,

\footnotetext{
${ }^{3}$ Ver: MAGISTER, S. Spaemann: È il caos ereto a principio con un tratto di penna. Settimo Cielo (28.04.2016). Disponível em: http://magister.blogautore.espresso.repubblica.it/2016/04/28/ spaemann-e-il-caos-eretto-a-principio-con-un-tratto-di-penna/. Acesso em: 10 nov. 2020.

${ }^{4}$ Francisco cita, aqui, respectivamente: uma passagem do discurso proferido no encerramento da XVI Assembleia Geral Ordinária dos Bispos (24 de outubro de 2015), publicado pelo L'Osservatore Romano (ed. semanal portuguesa, de 20 de outubro de 2015), n. 9 e uma afirmação da Comissão Teológica Internacional, feita no documento À procura de uma ética universal: um novo olhar sobre a lei natural (2009), n. 59.
} 
embora vivendo em contextos objetivamente "irregulares", tais pessoas não podem ser consideradas em estado de pecado, com tudo o que ele implica de rejeição, afastamento, ruptura, indiferença ao amor de Deus. Se, antes da $\mathrm{AL}$, a condição para os casais que viviam em situação dita "irregular" poder comungar era a abstinência sexual (JOÃO PAULO II, 1984, n. 84; daqui em diante $=\mathrm{FC}$ ), a partir dela este não é mais o critério por excelência, mas o juízo de consciência do próprio casal, considerando também "os sinais de amor que refletem de algum modo o amor de Deus" (AL, n. 294).

Aqui tocamos em outro ponto chave para compreender a oposição e rejeição à AL: o papel da consciência na decisão moral. Aos que reduzem a função da consciência à aplicação das normas morais, é muito difícil compreender a perspectiva pela qual Francisco se move. Para ele, "nos custa deixar espaço à consciência dos fiéis, que muitas vezes respondem da melhor forma que podem ao Evangelho no meio dos seus limites e são capazes de realizar o seu próprio discernimento perante situações em que se rompem todos os esquemas" (AL, n. 37). Reconhecer que "somos chamados a formar as consciências, não a pretender substituí-las" (AL, n. 37) é muito difícil para quem foi formado numa perspectiva meramente deontológica da moralidade, segundo a qual, no juízo moral, têm prioridade o dever, a norma, a lei, o princípio, a autoridade. $\mathrm{O}$ rigorismo que deriva de tal postura dificulta que o confronto com a perspectiva teleológica da moralidade seja feita e que se considerem, portanto, a intenção da pessoa envolvida, as circunstâncias concretas da ação, sua finalidade e consequências.

O fato de Francisco ter introduzido uma denominação às situações irregulares - situações "chamadas" irregulares - demonstra a complexidade de tais situações, muitas vezes de difícil discernimento. Mas significa, também, que devemos analisar com profundidade o que as fazem ser consideradas "irregulares". Seria empobrecer demais o significado de tais relações se "regulares/irregulares" se referisse exclusivamente à esfera normativa. Para Antonio Autiero e Stephan Goertz, tais adjetivos devem-se referir "à densidade do significado da vivência conjugal que se constrói" (AUTIERO; GOERTZ, 2017, p. 261). São muitas as relações conjugais que, com o tempo, deixam de ser uma íntima comunhão de vida e de amor. Também não são poucas as segundas uniões que se constituem naquilo que as primeiras núpcias deixaram de significar.

Resulta difícil compreender a postura de Francisco se não tivermos presente a centralidade do discernimento no seu magistério. Como ele mesmo deixa claro, as situações chamadas "irregulares" precisam ser discernidas. O que deveria presidir tal discernimento é a lógica que perpassa todas as ações de Jesus nos evangelhos: a lógica da acolhida e da integração. Tal lógica não exclui ninguém da misericórdia de Deus e não condena ninguém para sempre (AL, n. 297); pelo contrário, toma distância da outra lógica também presente nos evangelhos, que caracteriza as ações dos fariseus, a lógica 
da exclusão, marginalização e condenação. Os fariseus não se permitiam considerar, no juízo moral, a complexidade das situações e, muito menos, a bondade moral presente no esforço feito pelas pessoas para viverem do melhor modo possível nas condições em que se encontravam. Valia para eles o cumprimento da lei pela lei. Obedecer materialmente aos preceitos e às normas, sem exceção, era o que bastava e importava. Francisco tem clareza de que essa não foi a opção de Jesus e, portanto, não pode ser a opção da Igreja. As normas, os preceitos, as leis, os princípios - mesmo no caso de não admitirem exceções - valem em geral e precisam ser confrontados com a situação concreta na qual as pessoas se encontram. Essa confrontação faz parte do processo de discernimento e é exigida por ele. Tem razão André Luiz Boccato de Almeida ao afirmar que "seria uma miopia ético-teológica reduzir o bom discernimento das situações irregulares apenas à dimensão jurídico-canônica, em detrimento do complexo universo da subjetividade humana, ainda em processo de melhor explicitação pelas pesquisas interdisciplinares" (2017, p. 528).

Quando Francisco afirma que "já não é possível dizer que todos os que estão numa situação chamada 'irregular' vivem em estado de pecado mortal, privados da graça santificante" (AL, n. 301), ele tem presente a existência de fatores que limitam a capacidade de decisão das pessoas e até mesmo aumentam, diminuem ou anulam sua responsabilidade e culpabilidade moral. Isso implica colocar em discussão a existência de normas morais absolutas - sempre reconhecidas pela tradição - que valem, sem exceção, para todas as pessoas e em todas as circunstâncias e proíbem atos intrinsecamente maus, isto é, atos para os quais não existe qualquer justificativa possível. É nessa esteira que se situa a AL. No entanto, como Francisco assumiu a orientação personalista na abordagem da sexualidade - sugerida pelo Concílio Vaticano II -, a definição do que é lícito ou ilícito, nesse campo, fundamenta-se "na natureza da pessoa e dos seus atos" (GS, n. 51) e não numa natureza abstrata. Concretamente, isso significa que a categoria lícito/ilícito refere-se a tudo o que respeita ou fere a dignidade da pessoa e a sua integridade corporal e promove os seus direitos fundamentais ou atenta contra eles (AUTIERO; GOERTZ, 2017, p. 268). Tal perspectiva nos obriga a rever se o que até hoje, no campo da sexualidade, categorizamos como atos intrinsecamente maus são maus de fato.

\section{A integração entre as dimensões objetiva e subjetiva da moralidade}

A nota de rodapé n. 41, referente ao parágrafo 305, tornou-se a passagem mais controversa da AL. Ela afirma que, em certos casos, a pessoa que se encontra "no meio de uma situação objetiva de pecado", mas que "subjetivamente não seja culpável ou não o seja plenamente" (AL, n. 305), pode 
contar com "a ajuda dos sacramentos". Em nenhum momento Francisco afirma que os divorciados recasados podem comungar tranquilamente ou que está "suspenso" o ensinamento de que os atos sexuais só são lícitos dentro do contexto matrimonial. Não podemos dizer que, se até ontem uma determinada situação era considerada objetivamente pecaminosa, hoje ela tenha deixado de ser simplesmente porque o Papa deseja, como se Francisco tivesse declarado a "anistia geral para o pecado de adultério" (BUTTIGLIONE, 2017, p. 75). Se ontem João Paulo II rompeu com uma práxis secular - a de que os divorciados recasados eram excomungados -, convidando os divorciados recasados a participar da vida da Igreja (FC, n. 84), embora restringindo a participação à Comunhão àqueles que optassem por viver em plena continência, hoje Francisco deu um passo a mais: tais pessoas podem ser admitidas à Confissão, discernir a existência de circunstâncias atenuantes, receber a absolvição (se houver condições para isso) e comungar (sem a exigência da renúncia às relações sexuais). $\mathrm{O}$ que fica claro na AL é que Francisco propõe um caminho de conversão em que o fiel interrogue a sua consciência, fazendo-se ajudar por um diretor espiritual ou confessor; que inicie um caminho de discernimento espiritual. Rocco Buttiglione é incisivo ao afirmar que, ao fazer uso da faculdade de ligar e desligar concedida por Jesus, João Paulo II fez uma escolha disciplinar e Francisco, uma escolha pastoral (BUTTIGLIONE, 2017, p. 47). Embora ambos partam da mesma teologia do matrimônio, João Paulo II dá maior ênfase à dimensão objetiva da moralidade, enquanto Francisco privilegia a subjetiva. Para Paolo Carlotti, o "discernimento seletivo" feito por Francisco "constitui a singularidade e a novidade do serviço petrino" que ele presta à Igreja (CARLOTTI, 2017, p. 10).

Nenhuma novidade quanto à orientação dada por Francisco, a não ser o fato de ela ser dada a pessoas que vivem em situação objetiva de pecado. $\mathrm{O}$ fato de Francisco chamar a atenção para o cuidado quanto ao juízo sobre a responsabilidade subjetiva das pessoas envolvidas fez com que ele fosse acusado de favorecer o subjetivismo moral e relegar, assim, a bondade moral da ação à intenção do sujeito e às circunstâncias que a acompanham. Francisco sabe que nenhuma circunstância pode tornar bom um ato intrinsecamente mau, mas reconhece que as circunstâncias podem aumentar ou diminuir a responsabilidade moral da pessoa $(\mathrm{AL}, \mathrm{n}$. 302). Esse é o discernimento a ser feito durante a confissão. ${ }^{5}$ Acredito que

\footnotetext{
${ }^{5}$ Como bem adverte Carlotti, não é possível saber a priori o grau de compreensão e de liberdade do sujeito numa determinada ação, mas apenas a posteriori, isto é, depois de analisar e avaliar a "intensidade" da sua "presença" naquilo que faz (CARLOTTI, 2017, p. 73). Sendo assim, compreendem-se mais facilmente duas afirmações feitas por Francisco: "Um juízo negativo sobre uma situação objetiva não implica um juízo sobre a imputabilidade ou a culpabilidade da pessoa envolvida" (AL, n. 302); "O grau de responsabilidade não é igual em todos os casos, e podem existir fatores que limitam a capacidade de decisão. Por isso, enquanto se deve expressar claramente a doutrina, é preciso evitar juízos que não levam em consideração a complexidade das diversas situações e é necessário prestar atenção ao modo como as pessoas vivem e sofrem por causa da sua condição" (AL, n. 79).
} 
Buttiglione tem razão quando não apenas se refere ao escândalo que pode ser provocado por aqueles que vivem numa situação pública de pecado e aproximam-se da Comunhão, como também ao escândalo que do mesmo modo pode causar a "apostasia de massa" - visto ser o divórcio um fenômeno de massa atualmente - se os divorciados recasados abandonam a Igreja e a educação cristã dos filhos (2017, p. 40). Se o número daqueles que vivem em situações chamadas "irregulares" aumenta dia a dia na Igreja, aumenta também o número daqueles que, mesmo estando numa situação chamada "irregular", podem estar subjetivamente na graça de Deus. Diante do risco de deixar que os fiéis se percam por estarem privados do sustento sacramental, Francisco opta por um risco menos grave, o de que alguns fiéis possam aproximar-se da Comunhão sem estar, ao menos objetivamente, em estado de graça. É evidente que Francisco não diz isso, mas é o que pode ser deduzido da proposta que faz quando afirma:

compreendo aqueles que preferem uma pastoral mais rígida, que não dê lugar a confusão alguma; mas creio sinceramente que Jesus Cristo quer uma Igreja atenta ao bem que o Espírito derrama no meio da fragilidade: uma Mãe que, ao mesmo tempo que expressa claramente a sua doutrina objetiva, 'não renuncia ao bem possível, ainda que corra o risco de sujar-se com a lama da estrada' (AL, n. 308).

Nessa perspectiva, maximizar o bem dos fiéis e minimizar os riscos que uma nova atitude pastoral comporta é tarefa a ser assumida por todos e cada um (BUTTIGLIONE, 2017, p. 40).

Na época da publicação da AL, Francisco chegou a ser acusado de propor à Igreja uma doutrina herética ao admitir que seria melhor ter relações adúlteras do que viver como irmão e irmã. Em nenhum momento Francisco afirma ou sugere isso. Muito pelo contrário:

há uma questão que sempre se deve levar em consideração, para nunca se pensar que se pretende diminuir as exigências do Evangelho. A Igreja possui uma sólida reflexão sobre os condicionamentos e as circunstâncias atenuantes. (...) Os limites não dependem simplesmente de um eventual desconhecimento da norma. Uma pessoa, mesmo conhecendo bem a norma, pode ter grande dificuldade em compreender 'os valores inerentes à norma' ou pode encontrar-se em condições concretas que não lhe permitem agir de maneira diferente e tomar outras decisões sem uma nova culpa (AL, n. 301).

Viver como irmão e irmã, isto é, sexualmente abstinentes, é um discernimento a ser feito pelo casal, considerando todos os elementos envolvidos na questão. Francisco certamente não descarta essa possibilidade, mas não a impõe, como fez João Paulo II ao colocá-la como condição para a Comunhão - a meu ver, uma "solução" pastoral cosmética, bastante "irreal e não verificável na prática" (ERNST, 2017, p. 128). Na esteira de Francisco, não seria imprudente nem errôneo dizer que a lei da gradualidade deve ser considerada também neste âmbito de decisão. 
Acredito que Walter Kasper tem razão ao qualificar de "grotesco" o fato de a AL ter sido reduzida a uma questão pastoral premente, mas que, em nenhum momento, poder ser considerada a questão central ou o tema central da AL. Isso fez com que, nesses cinco anos, a "visão profética" da AL fosse desconsiderada e o diálogo intraeclesial se caracterizasse por ser um "diálogo de surdos", atrasando, dessa forma, uma caminhada conjunta (2019, p. 12-14). Além disso, Kasper afirma que, na perspectiva do decreto do Concílio de Trento sobre a Eucaristia,

dificilmente dá para entender o alvoroço que se formou por causa dessa nota, uma vez que o Concílio de Trento consignou expressamente que a eucaristia é um remédio que visa livrar o ser humano dos pecados do cotidiano e preservá-lo dos pecados graves (DH, n. 1638). O respectivo cânone reforça ainda mais esse entendimento ao frisar que o fruto da eucaristia é o perdão dos pecados, mesmo sem fazer nenhuma referência restritiva aos pecados veniais (DH, n. 1655). Quem haveria de negar, portanto, que a recepção do sacramento da eucaristia pode ser recomendável em determinadas situações chamadas irregulares? (2019, p. 62-63).

\section{A urgência de reconsiderar algumas ambiguidades herdadas da tradição}

Pergunto-me se, por trás das críticas feitas a Francisco por causa da AL, não estão algumas contradições herdadas de uma tradição que precisaria ser colocada em discussão. Ouso apontar, aqui, três delas: 1. o princípio segundo o qual é o consentimento que fundamenta o matrimônio e o entendimento de que o amor é o motivo ético central da união matrimonial "ainda" convivem com um elevado número de proibições restritivas no campo da sexualidade e com uma rígida limitação da expressão do desejo na vida conjugal; 2. a sexualidade, compreendida como dimensão constitutiva da pessoa, e o amor, entendido como critério por excelência de humanização da sexualidade, "ainda" são categorias restritas ao âmbito matrimonial heterossexual; 3. a prioridade dada à categoria personalista na reflexão moral "ainda" convive com uma compreensão redutiva de natureza humana, vinculada mais a leis biológicas do que à capacidade de a pessoa discernir de forma autônoma e responsável. Em outras palavras, tais exemplos ilustram bem que precisamos superar algumas ambiguidades relativas tanto à compreensão quanto ao ensino sobre sexualidade-matrimônio-família.

Pergunto-me, ainda, se a teologia do corpo de João Paulo II não contribuiu para prolongar, no tempo, tais contradições. Explico-me: na Humanae Vitae, Paulo VI assume uma perspectiva personalista quando se refere ao amor conjugal, mas opta pela justificativa jusnaturalista quando se refere a questões concretas de moral sexual, com todas as limitações ao juízo da consciência que tal justificativa implica. Ao postular a inseparabilidade entre os significados unitivo e procriativo do ato conjugal, Paulo VI dá 
às leis biológicas referentes à pessoa uma rígida obrigatoriedade moral na forma de uma norma que não admite exceção (2001, n. 12 e 10). Mas foi Karol Wojtyla quem forneceu a Paulo VI o substrato necessário - por meio da sua obra Amor e Responsabilidade ${ }^{6}$ - para que ele unisse a argumentação natural com a personalista, dando prioridade, porém, à natural: a ordem natural, como expressa o plano originário do Criador, está acima de qualquer mudança histórica, sociocultural e pessoal e, portanto, no exercício da sexualidade, o ser humano deve submeter-se a ela. João Paulo II fará com que a Familiaris consortio - profundamente influenciada pelas suas catequeses sobre a teologia do corpo - dê ao ensinamento da Humanae Vitae um tom de definitividade (2005, p. 524-525). Não podemos desconsiderar que a tradição da doutrina da Igreja é viva; aproximar-se teologicamente dela significa que, diante dos sinais dos tempos, há dois caminhos possíveis: fechar-se numa doutrina constante e imutável - e, com isso, beneficiar a verdade herdada da tradição - ou abrir-se para enriquecê-la e aprofundá-la à luz do Espírito - beneficiando, dessa forma, aqueles que desejam caminhar na verdade herdada da tradição.

Há muitos anos, tenho prestado atenção ao fenômeno do "cisma submerso" presente na Igreja (PRINI, 1999, p. 78). De um lado, temos o rigoroso ensinamento do Magistério sobre sexualidade; de outro, uma grande maioria de fiéis que não veem nele algum sentido. ${ }^{7}$ No campo pastoral, a opção quase sempre se dá pela flexibilidade quando se trata de aplicar a doutrina (GOERTZ; WITTING, 2017, p. 35) ou de "saídas práticas" encontradas pelos sujeitos: os pastores fazem vistas grossas aos comportamentos não conformes à doutrina e os fiéis fazem o que podem ou ignoram as orientações do Magistério (PASSOS, 2016, p. 38). ${ }^{8}$ Além da ambiguidade dessa contradição, há outra relativa a ela que não faz bem à Igreja porque compromete a sua credibilidade: continuar propondo como um bem ou como algo bom o que não é mais adequado à realidade, o que não tem mais que ver com pessoas concretas, inseridas num determinado contexto sociocultural. A dissonância entre o ensino do Magistério e a vivência dos fiéis não pode continuar se prolongando no tempo como se nada estivesse acontecendo. Considerar o senso comum dos fiéis como mera retórica no

\footnotetext{
${ }^{6}$ WOJTYLA,1983. É muito importante ter presente o estudo de: BARBERI, M. J.; SELLING, J. A. The Origin of Humanae Vitae and the Impasse in Fundamental Theological Ethics. Louvain Studies, n. 37, p. 364-389, 2013. Disponível em: https://theo.kuleuven.be/apps/christian-ethics/ sources/Barberi-Selling.pdf. Acesso em: 10 nov. 2020.

${ }^{7}$ KASPER chama a atenção para o fato de que a pesquisa de opinião promovida em vista do Sínodo sobre a Família "deixou claro que existe uma grande distância entre a doutrina da Igreja sobre matrimônio e família, de um lado, e a convicção da fé vivida por um grande número de cristãos, de outro. Muitos cristãos já não conseguem compreender certas implicações da moral sexual, matrimonial e familiar da Igreja" (KASPER, 2019, p. 18).

${ }^{8}$ As reflexões propostas, em 1989, por Bernhard Häring sobre uma possível pastoral para as pessoas divorciadas - apesar de o foco ser a doutrina da indissolubilidade do matrimônio -, se tivessem sido acolhidas, teriam antecipado, em décadas, algumas discussões levantadas hoje pela AL. Ver: HÄRING, 1990.
} 
campo da moral sexual é uma postura que não mais se sustenta, já que no campo da moral social ele é um importante elemento de discernimento. ${ }^{9}$ Se não prestarmos atenção a isso, as palavras do sábio Frei Bernardino Leers - ditas há quase três décadas - continuarão a nos envergonhar:

Enquanto há mais de vinte anos as discussões continuam entre os teóricos, o clero e as autoridades eclesiásticas, parece que os práticos, que são os leigos casados e pais de família, abandonam cada vez mais o campo da briga e seguem suas consciências na construção da própria convivência afetiva, sexual e familiar, e na solução dos problemas morais que esta construção criativa enfrenta e que eles tentam encaminhar de modo melhor possível (1992, p. 7).

\section{A primazia do amor e da misericórdia em relação à doutrina}

É triste fazer a afirmação que segue, mas é preciso: após cinco anos, a AL não alcançou unanimidade na Igreja e parece que não alcançará tão cedo. Embora não seja essa a pretensão de Francisco, o fato é que o empenho feito por muitos para descaracterizar a AL como se ela fosse apenas uma opinião particular do Papa e, portanto, não um ato magisterial dificulta e retarda o processo de aceitação e assimilação do seu conteúdo. Há ainda os que procuram diminuir a força do ensinamento de Francisco classificando-o como meramente pastoral e não doutrinal. Ao se opor a essas interpretações, o cardeal Christoph Schönborn - em entrevista a Antonio Spadaro - deixa claro que a AL é "um ato do magistério que atualiza no tempo presente o ensinamento da Igreja"; (...) "é o grande texto de moral que esperávamos desde os tempos do Concílio" (SPADARO, 2016b, p. 134 e 140); e que, a partir de agora, todos os documentos magisteriais sobre família, anteriores à $\mathrm{AL}$, devem ser lidos e interpretados à luz dela.

Para os opositores de Francisco, custa admitir que, com o processo sinodal que resultou na $\mathrm{AL}$, ele propôs à Igreja uma mudança de paradigma eclesiológico no enfrentamento de questões morais: o primado é dado ao amor e à misericórdia e não à doutrina. ${ }^{10}$ Para Stephan Goertz e Caroline Witting, trata-se de duas opções teológicas que constituem o fundamento da AL: o amor, como lei prioritária; a misericórdia, como fruto do amor (2017, p. 64-72). Intimamente relacionado com a sexualidade, com o matrimônio e com a família, o amor é entendido por Francisco na sua tríplice dimensão: querer o bem do outro (AL, n. 123), fazer o bem ao outro (AL, n. 94) e re-

\footnotetext{
${ }^{9}$ Ver: CURRAN, 1993, p. 536-558.

${ }^{10}$ Acredito ser muito acertada a observação feita por João Décio Passos de que com Francisco se deu o "resgate de um paradigma interrompido" (2018, p. 123). O evangélico paradigma do amor sempre esteve presente na tradição eclesial, mas por um longo período histórico resultou quase imperceptível nas formulações e práticas pastorais que priorizaram a dimensão objetiva da moralidade.
} 
conhecer-se imperfeito para realizar plenamente o outro (AL, n. 135). Quem ama é uma pessoa concreta que, aos poucos, aprende como amar de forma livre, autêntica e responsável. Tanto a compreensão do amor quanto a sua vivência estão, portanto, condicionadas ao processo de desenvolvimento e amadurecimento afetivo-sexual da pessoa, sujeitas a tudo o que faz parte de tal processo. $\mathrm{O}$ amor conjugal caracteriza-se por ser um projeto de vida comum, edificado tanto sobre a riqueza quanto sobre a fragilidade de cada um. Segundo Francisco, "o amor é artesanal": um ajuda o outro a crescer, a "moldar-se na sua própria identidade" (AL, n. 221); um ajuda e espera o outro a crescer, buscando a unidade no respeito e na valorização da diversidade. A misericórdia, como fruto do amor, abre para quem ama a dimensão de eternidade, ou seja, ela ajuda quem ama a não se cansar nem desistir do outro. $\mathrm{O}$ fato de Deus nos amar dessa forma faz com que Francisco acredite firmemente que o caminho a ser percorrido não é o de impor condições à misericórdia (AL, n. 310), mas o de inclinar-se para "compreender, perdoar, acompanhar, esperar e sobretudo integrar" (AL, n. 312). Para Francisco, o primado do amor e da misericórdia, se assumido com os mesmos sentimentos e atitudes por meio dos quais Deus manifesta Seu amor para conosco, constitui não tanto um novo paradigma eclesiológico no enfrentamento de questões morais, mas a essência mesmo do Evangelho:

Embora não cesse jamais de propor a perfeição e convidar a uma resposta mais plena a Deus, 'a Igreja deve acompanhar, com atenção e solicitude, os seus filhos mais frágeis, marcados pelo amor ferido e extraviado, dando-lhes de novo confiança e esperança, como a luz do farol de um porto ou de uma tocha acesa no meio do povo para iluminar aqueles que perderam a rota ou estão no meio da tempestade'. Não esqueçamos que, muitas vezes, o trabalho da Igreja é semelhante ao de um hospital de campanha (AL, n. 291).

No entanto, não é nessa perspectiva que todos compreendem Francisco. Basta considerar, por exemplo, dois ex-membros da Pontifícia Academia para a Vida: Robert Spaemann e Josef Seifert. Ambos pedem que Francisco substitua os erros da AL pela verdade, as falsas interpretações pelas verdadeiras, as afirmações objetivamente confusas por aquelas que são claras e o anúncio de uma falsa misericórdia por outro mais verdadeiro. Sugerem que a posição do Papa constitui uma "violência à misericórdia de Deus". No centro das acusações a Francisco está a convicção de que a Igreja não tem o poder, sem que haja uma prévia conversão, de sancionar positivamente as relações sexuais irregulares por meio da administração dos sacramentos, concedendo por antecipação a misericórdia de Deus (MAGISTER, 2016; SEIFERT, 2016). Buttiglione responde detalhadamente a cada uma das críticas feitas à AL e, por isso, não me detenho nessa tarefa (2017). ${ }^{11}$ Saliento

${ }^{11}$ Assim como feito por Buttiglione - embora numa perspectiva completamente contrária -, Alvarado Marambio apresenta uma análise detalhada do que ele chama "passagens ambíguas" da AL e propõe o que considera ser uma interpretação adequada e correta de tais passagens. O autor pretende deixar claro que: 1. a AL não abraçou a "proposta Kasper", segundo a qual 
apenas que a $\mathrm{AL}$ - por ser acusada de não apresentar nenhuma definição convincente de "condições atenuantes", já que essas influenciam o juízo de valor das assim chamadas situações "irregulares", acabaria por levar todas as pessoas a serem admitidas à Comunhão - "ressuscitou" os opositores da ética da situação e evidenciou a falta de clareza da parte de muitos em relação às fontes da moralidade.

Faz parte da tradição da Igreja - sintetizada pelo Catecismo da Igreja Católica nos números 1750-1754 - o ensinamento de que a qualidade moral de uma ação e a culpa subjetiva de quem age derivam de três fontes: do objeto escolhido, da intenção do sujeito e das circunstâncias da ação (CIC, n. 2017). Os críticos de Francisco conhecem esse ensinamento e sabem que não se pode emitir um juízo moral sobre um determinado comportamento levando-se em conta apenas uma dessas três fontes. Sabem, sobretudo, que Francisco jamais cairia nesse erro. Mas não conseguem admitir o valor e o significado que ele dá aos princípios sobre os quais edifica a sua proposta: 1. o tempo é superior ao espaço; 2 . a unidade prevalece sobre o conflito; 3. a realidade é mais importante que a ideia; 4 . o todo é superior à parte. Tais princípios são amplamente explicados por Francisco na Evangelii Gaudium (FRANCISCO, 2013, n. 222-237; daqui em diante = EG) e, por uma questão de perspectiva de abordagem do tema, não vou aprofundá-los aqui, mas apenas propor alguns elementos que deles derivam para a compreensão dos conflitos que subjazem à não aceitação do ensinamento da AL. ${ }^{12}$

O tempo é superior ao espaço: entre a plenitude e o limite há sempre alguma tensão. O tempo "refere-se à plenitude como expressão do horizonte que se abre diante de nós, e o momento é expressão do limite que se vive num espaço circunscrito" (EG, n. 222). Trata-se de um princípio que abre o futuro como possibilidade de realização das promessas do presente e permite, dessa forma, "trabalhar a longo prazo, sem a obsessão pelos resultados imediatos" (EG, n. 222). Dar prioridade ao tempo significa reconhecer que é preciso renunciar à tentação de controlar todos os espaços e iniciar processos que favoreçam a liberdade responsável, a autêntica autonomia e o crescimento integral, processos que permitem à pessoa ter consciência de onde ela se encontra em sentido existencial, onde está posicionada "do ponto de vista das suas convicções, dos seus objetivos, dos seus desejos, do seu projeto de vida" (AL, n. 261). Significa, também, renunciar à pretensão de controlar tudo e todos por meio da imposição de

poderiam ser admitidas à Comunhão pessoas em situação notória de adultério permanente; 2. a AL não propõe uma ética da situação, barateando os mandamentos da lei de Deus; 3. a AL não contradiz nem rejeita o Decreto sobre a Justificação, do Concílio de Trento, visto que nenhum "discernimento" pode justificar o que é injustificável. Ver: ALVARADO MARAMBIO, 2016, p. 389-414.

${ }^{12}$ Embora Francisco aplique tais princípios no âmbito sociocultural, vou empregá-los aqui para evidenciar quanto contribuem para o devido enquadramento de questões morais em outros âmbitos de ação. 
normas ou intervenções magisteriais. Se quem conduz a Igreja no tempo é o Espírito, é preciso que tenhamos a devida paciência para que, num determinado espaço, saibamos também lidar com o que poderia ser ideal, mas não é, devido às limitações próprias da situação concreta em que as pessoas vivem. ${ }^{13}$ Para Francisco,

nem todas as discussões doutrinais, morais ou pastorais devem ser resolvidas através de intervenções magisteriais. Naturalmente, na Igreja, é necessária uma unidade de doutrina e práxis, mas isto não impede que existam maneiras diferentes de interpretar alguns aspectos da doutrina ou algumas consequências que decorrem dela (AL, n. 3).

A unidade prevalece sobre o conflito: mesmo quando o objetivo é a unidade, não é possível ignorar ou dissimular os conflitos; tem-se de aceitá-los, resolvê-los e transformá-los "no elo de ligação de um novo processo" (EG, n. 227). Para Francisco, isso é muito importante se quisermos "desenvolver uma comunhão nas diferenças" (EG, n. 228). O reconhecimento dos próprios erros é o primeiro passo para que sejam encontradas formas de interação orientadas para o bem de todas as pessoas envolvidas numa relação. No entanto, ninguém é chamado a fechar-se nas próprias limitações, conflitos e erros se não quiser perder a própria perspectiva, reduzir o próprio horizonte, fragmentar a própria realidade e projetar no outro ou numa determinada instituição os próprios dilemas. Para Francisco, "quando paramos na conjuntura conflitual, perdemos o sentido da unidade profunda da realidade" (EG, n. 226). Não são poucos os conflitos presentes numa relação conjugal; o fato de o casal ser chamado a formar "uma só carne" não implica que um deva se absorver no outro a ponto de perder a própria individualidade. $\mathrm{O}$ enfrentamento dos conflitos visa a unidade e não a uniformidade. $\mathrm{O}$ mesmo pode ser dito sobre a relação entre ensinamento magisterial e comportamento concreto dos fiéis. É preciso que haja unidade quanto ao essencial e respeito à diversidade quanto aos aspectos acidentais. O capítulo VIII da AL é a expressão mais evidente do esforço feito por Francisco para, sem mudar uma linha sequer da doutrina da Igreja sobre matrimônio e família, fazer prevalecer a unidade por meio de uma nova abordagem pastoral sobre os conflitos.

A realidade é mais importante que a ideia: com singular clareza, Francisco define a realidade como o que "simplesmente é", e a ideia como algo que se elabora (EG, n. 231). Para ele, "entre as duas, deve estabelecer-se um diálogo constante, evitando que a ideia acabe por separar-se da realidade" (EG, n. 231). É a ideia que deve estar "ao serviço da captação, compreensão e condução da realidade" (EG, n. 232) e não o contrário. Os princípios absolutos - inclusive os morais - são apenas ideias abstratas e, até mesmo pelo fato de facilmente serem transformados em ideologias, não servem, em si mesmos, para mudar a realidade. $\mathrm{O}$ mesmo acontece

13 SPADARO, 2013, p. 468. Ver também: MASPERO, 2014. 
com a expressão religiosa da fé: ela também pode se tornar uma mera ideologia quando absolutiza soluções disciplinares e segurança doutrinária, sem se dar conta de que o Espírito não é prisioneiro de nenhum passado a ser "resgatado". Quando na AL Francisco propõe uma nova abordagem pastoral de situações moralmente conflitivas, ele chama a atenção para o fato de que a realidade não pode ser ignorada; ou melhor, a prioridade no juízo moral deve sempre ser dada à pessoa inserida numa situação concreta do que a uma doutrina, por mais "constante" que seja.

O todo é superior à parte: alargar o olhar para contemplar o todo permite reconhecer que, muitas vezes, um bem maior numa determinada situação ou para uma determinada pessoa pode trazer benefícios para todos (EG, n. 235). Francisco serve-se da figura geométrica do poliedro para explicitar isso, visto que este "reflete a confluência de todas as partes que nele mantêm a sua originalidade" (EG, n. 236). Mais do que interessado na real "superioridade" de um sobre o outro, o Papa está interessado em que o todo seja interpretado à luz das partes e as partes, à luz do todo. Para ele, ninguém pode ser excluso da colaboração com o bem comum; ninguém pode ficar perdido para sempre; ninguém pode ser posto para fora do banquete: "o Evangelho possui um critério de totalidade que lhe é intrínseco: não cessa de ser Boa-Nova enquanto não for anunciado a todos, enquanto não fecundar e curar todas as dimensões do homem, enquanto não unir todos os homens à volta da mesa do Reino" (EG, n. 237). À luz desse princípio, fica claro por que Francisco se aproxima pastoralmente dos casais em situações chamadas "irregulares" sem receio de abrir para eles as portas da acolhida, do acompanhamento, do discernimento e da integração.

Os elementos levantados pelos críticos de Francisco e os que compõem os quatro princípios tão caros a ele devem ser todos eles tomados em consideração, mesmo que, em determinados momentos e diante de determinadas situações, seja preciso fazer opções que manifestem claramente quais são as prioridades a serem consideradas e o porquê de não se poder abrir mão delas.

\section{A pastoralidade como critério hermenêutico na reflexão moral}

Diante do mal-estar provocado pela AL na Igreja, há quem procure eliminá-lo apelando para o argumento de que não muda nada na teologia do matrimônio, visto que a novidade da AL não está no campo teológico, mas disciplinar e, portanto, pastoral. A AL substituiu o primado dado até então à doutrina pelo primado das práticas concretas de amor e misericórdia, fazendo com que Francisco fosse o primeiro Papa a inaugurar, depois do Concílio Vaticano II, um ministério magisterial, por assim dizer, de caráter prioritariamente pastoral. Para Carlotti, 
Francisco não apenas procede da experiência pastoral para repensar a identidade da ética cristã e da sua específica reflexão teológica, mas a tem como constante e privilegiada referência, enucleando um 'círculo hermenêutico' que, com rigor, relaciona práxis e teoria, realidade concreta e identidade abstrata, confiando, assim, à teologia moral uma nova e delicada tarefa a ser pensada, procurando evitar, não apenas por declarada boa intencionalidade e vontade, os desvios extremistas dos pragmatismos e dos intelectualismos (2017, p. 15).

No entanto, dois problemas-chave permanecem: 1. o primado dado à misericórdia não resolve a questão das normas que contêm proibições absolutas; 2. sem uma renovada abordagem doutrinal, a mudança da práxis acaba dependendo de quem tem mais poder. Não quero, com isso, diminuir a importância da estrada aberta - e deixada em aberto - por Francisco ao relativizar aquilo que, até ontem, parecia dogma de fé em relação aos casais que vivem em situações chamadas "irregulares". Apenas pretendo responder a inquietações que continuam sendo provocativas.

Goertz e Witting têm razão quando afirmam que, "ao dirigir a atenção da ética ao sujeito da moral, ao colocar a pessoa no centro da reflexão moral", Francisco deixa claro que as leis não têm valor absoluto, "não são fins em si mesmas, mas têm um caráter relacional" e, portanto, o que é bom e justo tem que ver, primeiramente, com o respeito à pessoa, e as leis "devem referir-se aos valores a serem respeitados e promovidos" (GOERTZ; WITTING, 2017, p. 78). Na prática, isso significa que os juízos de valor não podem mais ter como referência única o que é considerado natural ou antinatural, nem um catálogo de normas que, desvinculadas do sujeito moral e da realidade concreta, pretendem ter valor universal e absoluto. $\mathrm{O}$ mesmo acontece com o primado dado ao amor nas relações: a afirmação do bem do outro pode se dar em qualquer relação, pondo em xeque a concepção de que, no juízo moral, a forma conta mais do que a substância.

Além disso, ao considerar a complexidade das situações nas quais as pessoas estão envolvidas, Francisco opta decididamente pela "arte do discernimento nas respectivas situações e circunstâncias da vida e, dessa forma, concede mais espaço à consciência" (MERKS, 2017, p. 132). Ele tem clareza de que nem a norma moral nem o Magistério da Igreja podem estar acima da consciência da pessoa (AL, n. 37). Para Francisco, a ética tem de se fundamentar na responsabilidade de a pessoa discernir as exigências que derivam de um processo de humanização - e, para os cristãos, as exigências que derivam do amor - e, nesse sentido, as normas morais não podem ser a última palavra ou instância de confronto. Karl-Wilhelm Merks é capaz de captar a questão-chave quando afirma que "não existe uma ética sem normatividade, sem princípios vinculantes, sem regras geralmente válidas e sem normas imperativas. A questão é apenas uma: como, em que modo e o quê é regulado e apresentado como vinculante" (MERKS, 2017, p. 134). A resposta a esse dilema exige continuamente que a pessoa se deixe interpelar pela norma e que esta seja confrontada pela 
situação concreta na qual a pessoa vive e a partir da qual é interpelada (MERKS, 2017, p. 158-159). Como bem afirma Francisco: "as consequências ou efeitos de uma norma não devem necessariamente ser sempre os mesmos" (AL, n. 300). Daí a importância do discernimento prático: "é verdade que as normas gerais apresentam um bem que nunca se deve ignorar nem transcurar, mas, na sua formulação concreta, não podem abarcar absolutamente todas as situações particulares" (AL, n. 304). É possível, mesmo no meio de situações-limite, encontrar caminhos de resposta a Deus e de crescimento na vida de graça e de caridade (AL, n. 305). A misericórdia, de fato, não resolve o problema das normas que contêm proibições absolutas, mas coloca-as no seu devido lugar. Não são elas que salvam e, muito menos, a adequação a elas, mas o esforço para praticar o bem possível em todas as situações, mesmo naquelas que, objetivamente, são consideradas "irregulares". Se, por um lado, "é preciso ter cuidado com a integralidade da doutrina moral da Igreja", por outro "sempre se deve pôr um cuidado especial em evidenciar e encorajar os valores mais altos e centrais do Evangelho, particularmente o primado da caridade como resposta à iniciativa gratuita do amor de Deus" (AL, n. 311).

É muito claro que Francisco não tem a intenção de se opor ao ensinamento tradicional da Igreja que considera objetivamente "irregular" a situação na qual vivem os divorciados recasados ou casais de segunda união. Ele apenas chama a atenção para o fato de que uma situação dita "irregular" não pode, tendo por base apenas a gravidade do objeto, ser considerada pecado grave ou mortal. Como afirma Stephan Ernst, "o Papa apenas recorre à reconsideração das circunstâncias atenuantes da culpa, que fazem parte dos elementos essenciais da teologia moral tradicional e da formulação doutrinal da moral" (2017, p. 128). No entanto, para bem da verdade, se considerarmos o que está em jogo na crítica feita à postura de Francisco, não é nem a situação objetiva na qual se encontra o casal que determina a gravidade do objeto, mas o fato de o casal, numa situação chamada "irregular", ser sexualmente ativo: "ao que tudo indica, o verdadeiro e próprio pecado consiste no fato de os divorciados recasados manterem relações sexuais fora do primeiro matrimônio, considerado indissolúvel" (2017, p. 123).$^{14}$ A análise fica ainda mais complicada se considerarmos que, para Francisco, a abstinência sexual entre tais casais não é "condição" para a recepção dos sacramentos.

\footnotetext{
${ }^{14}$ Carlotti, em sintonia com a FC 84, distingue o fato da convivência - um divorciado que se casa novamente - do pecado de convivência - a vida sexualmente ativa do divorciado recasado. Para ele, o pecado não é um fato; portanto a convivência, em si, não é pecaminosa. O pecado é uma decisão, isto é, se o casal optar por uma vida sexualmente ativa, sem qualquer esforço para evitá-la, aí sim estaria em estado de pecado. Caso o casal se empenhe, mas não consiga viver sem sexo, não estaria pecando, porque está lutando contra o pecado (2017, p. 76-77). Essa distinção, a meu ver, não ajuda, porque continua a superestimar o sexo como "lugar" de pecado e desconsidera o ponto nevrálgico afirmado por Francisco na AL 305: pode-se viver, sim, em graça de Deus numa situação "objetiva" de pecado.
} 
E aqui tocamos num dos nós que, a meu ver, está na base de várias posturas de oposição e indiferença à AL: no campo da sexualidade, o Magistério não se cansa de empenhar-se pela defesa intransigente de uma "doutrina constante", inegociável, cristalizada, mesmo se não significa muita coisa para a maioria dos fiéis. Como bem afirma Merks, justamente pela dificuldade de avaliar criticamente normas herdadas de uma tradição casuística, a moral sexual serve "de prova para a presumível natureza antiquada de toda a moral católica" (MERKS, 2017, p. 140). Francisco Javier de La Torre Diaz é ainda mais incisivo:

A moral sexual é o âmbito da Igreja mais separado da vida dos seres humanos em nossos países ocidentais. Nesses temas, os jovens (e muitos adultos) parecem estar escutando palavras de outro planeta, pouco razoáveis e plausíveis quando a moral se concretiza em normas mais detalhadas (2018, p. 243-244).

Apesar dos avanços na compreensão antropológica e teológica do amor e da sexualidade, no âmbito da vivência concreta da sexualidade, a moral da Igreja não avançou para além de uma ética rigorosamente normativa. Chegamos a um ponto que seria injusto afirmar que o conflito está apenas entre ensinamento do Magistério e vivência concreta dos fiéis. $\mathrm{O}$ fato de a doutrina em si não "fazer-se carne" na vida da maioria dos fiéis, faz com que tenhamos de questionar os fundamentos dessa própria doutrina (MERKS, 2017, p. 141).

Por isso acredito que, sem uma renovada abordagem doutrinal a respeito da sexualidade, a mudança da práxis acaba condicionada a quem tem mais autoridade ou poder. Afirmar que a AL é um mero desvio na rota constante empreendida pela Igreja ou que Francisco carece de competência hermenêutica significa negar que a AL foi "fruto de um amplo processo sinodal e eclesial" (SPADARO, 2016a, p. 108) - assumido plenamente por Francisco, inclusive pela acolhida substancial na AL da Relatio Finalis como se o Espírito Santo não guiasse e assistisse a Igreja nesse processo. Em outra instância, apresentei os traços característicos do fundamentalismo espelhados nas acusações ou cobranças feitas ao Papa Francisco e justifiquei por que a AL é a expressão mais autêntica de um magistério que se distancia do fundamentalismo ético-moral (ZACHARIAS, 2017, p. 223-269). No que se refere à moral sexual, a AL escancara o fato de que não é mais possível dar prioridade a leis, regras, normas e princípios, a atos isolados, a métodos dedutivos, prescindindo dos contextos históricos, culturais e relacionais nos quais as pessoas vivem, do esforço feito por elas para se abrirem e/ou se conformarem aos apelos evangélicos, mesmo em contextos considerados objetivamente desordenados e da confiança na misericórdia de Deus quando não se é capaz de viver plenamente o ideal proposto e/ ou abraçado (SALZMAN; LAWLER, 2016). Isso Francisco deixou muito claro. O que, a meu ver, ainda precisa ser revisado é o pressuposto de que a moral sexual católica tradicional - como é a moral sexual hoje - está fundamentada na Sagrada Escritura. Basta ter presente dois exemplos: 1. o 
"uso" da Sagrada Escritura no ensinamento sobre questões sexuais: quando muito, são citadas algumas passagens bíblicas como notas de rodapé nos documentos oficiais, completamente descontextualizadas e, portanto, carentes de validade exegética; 2 o matrimônio como único contexto lícito para as relações sexuais: assumir que o matrimônio seja o contexto ideal para relações de intimidade sexual não nos dá o direito de vincular à vontade de Deus que ele seja o lugar exclusivo para tais relações. A falta de aprofundamento dessas questões leva quem tem mais autoridade e poder a dificultar qualquer mudança na prática pastoral, como se isso constituísse um atentado contra a doutrina. Talvez seja esse o preço a pagar pelo fato de, no campo da moral sexual, a Igreja ter-se afastado do sensus fidei e da vida do Povo de Deus. ${ }^{15}$ Não podemos esquecer-nos de que os caminhos de crescimento na vida da graça podem ser múltiplos, que o discernimento necessário para descobri-los pode ser, inclusive, ação do próprio Deus na vida das pessoas e que "discernir com responsabilidade é uma norma normans na comunidade eclesial (ALMEIDA, 2017, p. 534).

O que Francisco faz na $\mathrm{AL}$ - dar prioridade ao amor de Deus e não à doutrina eclesial - torna-se um "critério hermenêutico" para esclarecer outro aspecto muito importante da AL, o significado de gradualidade (FUMAGALLI, 2017, p. 56). Tradicionalmente, o conceito de lei da gradualidade, aplicado ao contexto da moral cristã, tem favorecido avaliar o comportamento à luz dos passos que a pessoa pode e poderá dar na situação concreta em que estiver e não apenas em relação à conformidade com a norma estabelecida. Francisco, por sua vez, assume-o numa outra perspectiva; para ele, a gradualidade deve referir-se "à dinâmica amorosa mais do que à normativa estática" (FUMAGALLI, 2017, p. 57). Em outras palavras, a pessoa é chamada a crescer gradativamente na prática do amor, tarefa essa sempre possível e nunca realizada de forma definitiva. Para expressar essa realidade, Francisco prefere falar de "caminho de contínuo crescimento" (AL, n. 134), "etapas de crescimento" (AL, n. 308). Tanto o chamado ao amor quanto o mandamento do amor são válidos para todas as pessoas em todos os lugares. Mais do que uma norma externa, trata-se de um "dinamismo interior" que possibilita à pessoa, mesmo em contextos objetivamente "irregulares" ou distantes do ideal desejado, percorrer "um processo de conversão determinado pelo sim ao bem e pelo não ao mal, mas que não conhece apenas o bem e o mal, como também o melhor e o pior" (FUMAGALLI, 2017, p. 58). Aqueles que acreditam ser suficiente o cumprimento ou não das normas, para situar a pessoa num estado objetivo de graça ou de pecado, desconhecem que até mesmo tais estados são realidades dinâmicas e não estáticas. Tanto um quanto outro estado

\footnotetext{
${ }^{15}$ Se considerarmos que na esfera da moral social conta muito a responsabilidade individual, a decisão de consciência, a abertura à realidade, a colaboração dos fiéis, torna-se ainda mais urgente o apelo para que os fundamentos da moral sexual sejam revistos. Ver: CURRAN, 1993, p. 536-558.
} 
podem crescer ou diminuir. Sabedor dessa realidade, Francisco reconhece que todos devem, progressivamente, amadurecer a própria capacidade de amar, com os olhos voltados para a plenitude ainda não alcançada, mas com a humildade necessária para reconhecer que a perfeição, a pureza e a coerência que pretendemos das relações interpessoais só as encontraremos no Reino definitivo (AL, n. 325).

\section{Conclusão}

Posicionar-se na contramão de abstracionismos e idealismos mirabolantes, artificiosos, inacessíveis e impraticáveis - aos quais no campo da moral sexual nos habituamos - faz com que Francisco pague um alto preço, inclusive o de não poder testemunhar a mudança que a AL poderia produzir na prática pastoral da Igreja. Habituado a dizer como a vida deve ser vivida, parte do Magistério da Igreja corre o risco de não "prestar atenção" ao que a vida mesma tem a dizer e, com isso, reduzir a moral cristã a uma espécie de produto final a ser apenas homologado, porque já suficientemente conhecido e constantemente reafirmado. Francisco situa-se numa perspectiva completamente contrária (AL, n. 2, 3, 37, 49, 305, 311, 312). Vale recordar, aqui, a afirmação feita por ele um ano antes da AL, que a perpassa completamente: "As questões do nosso tempo, as suas obras, batalhas, sonhos e preocupações, possuem um valor hermenêutico que não podemos ignorar se quisermos deveras levar a sério o princípio da encarnação. As suas perguntas ajudam-nos a questionar-nos, as suas questões interrogam-nos" (FRANCISCO, 2015). ${ }^{16}$

Convicto de que se faz urgente ajudar as pessoas a encontrar e acolher Cristo na vida cotidiana concreta, a ampliar e não restringir as possiblidades de liberdade, a despertar a confiança na graça de Deus - todas essas tarefas da reflexão e proposta moral -, Francisco não dispensa a reflexão moral do devido rigor científico, da atenção à realidade concreta, do amor pela Igreja, do discernimento pessoal e comunitário e da oração feita de joelhos. Para ele, inclusive a teologia moral não deveria ser outra coisa senão uma teologia que se põe de joelhos, em atitude de humilde submissão (FRANCISCO, 2016b, p. 422). De joelhos para que a própria identidade pessoal e o

\footnotetext{
${ }^{16}$ Francisco refere-se, aqui, ao fato de a doutrina não poder ser considerada como "um sistema fechado, privado de dinâmicas capazes de gerar perguntas, dúvidas, interrogações. Ao contrário, a doutrina cristã tem um rosto, um corpo, tem carne, chama-se Jesus Cristo e é a Sua Vida que é oferecida de geração em geração a todos os homens e em todos os lugares. Preservar a doutrina requer fidelidade ao que recebemos e - ao mesmo tempo é preciso ter em consideração o interlocutor, o destinatário, que se deve conhecer e amar" (2015a). Na Exortação Apostólica Gaudete et Exsultate, Francisco une essas duas citações no parágrafo 44. Ver: FRANCISCO, 2018.
} 
próprio trabalho teológico sejam continuamente definidos e/ou redefinidos por um chamado - a vontade do Pai - que constantemente provoca; por uma pessoa - a pessoa de Jesus, o Cristo - que continuamente seduz; e por uma força-ação - o Espírito Santo de Deus - que ininterruptamente abre o olhar, toca o coração e leva a ver-sentir a realidade com os olhos e o coração do Pai, que é rico em misericórdia. ${ }^{17}$

Colocar-se de joelhos impulsionará a teologia moral a buscar "aquela renovação sábia e corajosa que é requerida pela transformação missionária duma Igreja 'em saída'" (FRANCISCO, 2018, n. 3) e pôr-se também ela em atitude "de saída", não hesitando, assim, em "sujar as mãos" (FRANCISCO, 2019) no envolvimento concreto com os problemas, as fragilidades e os sofrimentos dos filhos e filhas de Deus, para oferecer-lhes "a força sanadora da graça e da luz do Evangelho" (AL, n. 49).

Passaram-se cinco anos desde que Francisco apresentou à Igreja a AL. Para Passos, a parábola do semeador - com a devida interpretação feita pelo próprio Jesus - ajuda-nos a compreender que a recepção do documento está intimamente relacionada com o terreno onde ele, como semente, foi lançado, e propõe, dessa forma, uma análise muito lúcida da questão (2016, p. 85-92). Depois de cinco anos, é hora de superar a mera disputa de conceitos, a postura arrogante de quem não se deixa interpelar pelo Espírito, a atitude medrosa de quem acredita que tudo pode "descambar" pelo fato de o discernimento não poder ser, a priori, controlado. Vale hoje, como nunca, a convicção de que, em meio a tantos terrenos duvidosos, há um terreno bom, porque fecundo. Lançar a semente - a própria AL - nesse terreno não pode nem deve inibir a ação voltada para os outros tipos de terrenos - menos acolhedores, mais áridos, menos preparados, mais impenetráveis - na certeza de que a proposta de um novo modo de viver o amor evangélico é capaz de superar tudo, inclusive a tentativa de calar a voz profética.

\footnotetext{
${ }^{17}$ Vale a pena ter presente a reflexão proposta por Conor M. Kelly sobre o papel do teólogo moralista depois da AL. O autor, à luz da abordagem que Francisco faz da consciência e do discernimento na $\mathrm{AL}$, sugere que cabe ao teólogo moralista empenhar-se para "criar uma cultura do discernimento na Igreja" como forma de, "honrar a dignidade da consciência" (2016, p. 940 e 948).
} 


\section{Siglas}

$\mathrm{AL}=$ Amoris Laetitia

$\mathrm{CIC}=$ Catecismo da Igreja Católica

DH $=$ DENZINGER, H.; HÜNERMANN, P.

$\mathrm{EG}=$ Evangelii Gaudium

$\mathrm{FC}=$ Familiaris Consortio

$\mathrm{HV}=$ Humanae Vitae

\section{Referências}

ALMEIDA, A. L. B. de. O discernimento da consciência na Exortação Apostólica Amoris Laetitia. Revista Eclesiástica Brasileira, Petrópolis, v. 77, n. 307, p. 520-535, 2017.

ALVARADO MARAMBIO, J. T. Acompañar, discerner e integrar la fragilidad. El capítulo VIII de Amoris Laetitia. Medellín, v. XLII, n. 165, p. 389-414, 2016.

AUTIERO, A.; GOERTZ, S. A proposito di dubbi, errori e distinzioni. Una postfazioni. In: GOERTZ,S.; WITTING, C. (A cura di). Amoris Laetitia: un punto di svolta per la teologia morale? Cinisello Balsamo (Milano): San Paolo, 2017. p. 257-269.

BOGNER, D. Um cenno di cambiamento. L'ambivalenza della "gradualità" in Amoris Laetitia. In: GOERTZ, S.; WITTING, C. (A cura di). Amoris Laetitia: un punto di svolta per la teologia morale? Cinisello Balsamo (Milano): San Paolo, 2017. p. 163-180.

BUTTIGLIONE, R. Risposte amichevoli ai critici di Amoris Laetitia. Milano: Ares, 2017.

CARLOTTI, P. La morale di Papa Francesco. Bologna: EDB, 2017.

CATECISMO DA IGREJA CATÓLICA. Novíssima edição de acordo com o texto oficial em latim. 4. ed. Brasília: CNBB, 2017.

CURRAN, C. E. Official Catholic Social and Sexual Teachings: A Methodological Comparison. In: CURRAN, C. E.; McCORMICK, R. A. (Eds.). Dialogue About Catholic Sexual Teaching. Mahwah, New Jersey, 1993. p. 536-558. (Readings in Moral Theology, n. 8).

DE LA TORRE DÍAZ, F. J. Cincuenta años de la Humanae Vitae: una meditación sobre el silencio y el diálogo de la Iglesia con la experiencia humana de la sexualidad. Perspectiva Teológica, Belo Horizonte, v. 50, n. 2, p. 219-246, 2018.

DENZINGER, H.; HÜNERMANN, P. (Ed.). Compêndio dos símbolos, definições e declarações de fé e moral. São Paulo: Paulinas / Loyola, 2007.

ERNST, S. Situazioni “irregolari” e colpa personale in Amoris Laetitia. Una frattura con la tradizione dottrinale. In: GOERTZ, S.; WITTING, C. (A cura di). Amoris Laetitia: un punto di svolta per la teologia morale? Cinisello Balsamo (Milano): San Paolo, 2017. p. 112-129.

FRANCISCO, Papa. Evangelii Gaudium. Exortação Apostólica sobre o anúncio do Evangelho no mundo atual. São Paulo: Paulus/Loyola, 2013.

FRANCISCO, Papa. Mensagem-video ao Congresso Internacional de Teologia da Pontifícia Universidade Católica Argentina (1 a 3 de setembro de 2015a). Disponível em: http:// www.vatican.va/content/francesco/pt/messages/pont-messages/2015/documents/ 
papa-francesco_20150903_videomessaggio-teologia-buenos-aires.html. Acesso em: 30 nov. 2020.

FRANCISCO, Papa. Discurso proferido por ocasião da comemoração do Cinquentenário da Instituição do Sínodo dos Bispos (17.10.2015b). Disponível em: http://www.vatican. va/content/francesco/pt/speeches/2015/october/documents/papa-francesco_20151017_ 50-anniversario-sinodo.html. Acesso em: 30 nov. 2020.

FRANCISCO, Papa. Amoris Laetitia. Exortação Apostólica Pós-Sinodal sobre o amor na família. São Paulo: Loyola, 2016a.

FRANCISCO, Papa. "Avere coraggio e audacia profética". Dialogo di papa Francesco con i gesuiti riuniti nella $36^{\text {a }}$ Congregazione Generale. La Civiltà Cattolica, Itália, IV, n. 3995, 417-431, $2016 b$.

FRANCISCO, Papa. Gaudete et Exsultate. Exortação Apostólica o chamado à santidade no mundo atual. São Paulo: Paulus, 2018.

FRANCISCO, Papa. Discurso aos professores e aos estudantes da Academia Alfonsiana Instituto Superior de Teologia (09.02.2019). Disponível em: http://www.vatican.va/ content/francesco/pt/speeches/2019/february/documents/papa-francesco_20190209_ accademia-alfonsiana.html. Acesso em: 30 nov. 2020.

FUMAGALLI, A. L'Amore in Amoris Laetitia: ideale, cammino, fragilità. Cinisello Balsamo (Milano): San Paolo, 2017.

GOERTZ, S.; WITTING, C. Un punto di svolta per la Teologia Morale? Contesto, ricezione ed ermeneutica di Amoris Laetitia. In: GOERTZ, S.; WITTING, C. (A cura di). Amoris Laetitia: un punto di svolta per la teologia morale? Cinisello Balsamo (Milano): San Paolo, 2017. p. 13-79.

HÄRING, B. Existe saída? Para uma pastoral dos divorciados. São Paulo: Loyola, 1990.

JOÃO PAULO II, Papa. Homem e mulher o criou: catequeses sobre o amor humano. Bauru: EDUSC, 2005.

JOÃO PAULO II, Papa. Familiaris Consortio. Exortação Apostólica sobre a função da família cristã no mundo de hoje. São Paulo: Paulinas, 1984.

KASPER, W. Il vangelo della famiglia. Brescia: Queriniana, 2014.

KASPER, W. A mensagem de Amoris Laetitia: um debate amigável. São Paulo: Loyola, 2019.

KELLY, C. M. The Role of the Moral Theologian in the Church: A Proposal in Light of Amoris Laetitia. Theological Studies, USA, v. 77, n. 4, p. 922-948, 2016.

LEERS, B. Família, casamento, sexo: por uma nova prática pastoral. Petrópolis: Vozes, 1992.

MAGISTER, S. Spaemann: è il caos ereto a principio con un tratto di penna. Settimo Cielo (28.04.2016). Disponível em: http://magister.blogautore.espresso.repubblica. it/2016/04/28/spaemann-e-il-caos-eretto-a-principio-con-un-tratto-di-penna/. Acesso em: 10 nov. 2020.

MASPERO, G. Il tempo superiore allo spazio (EG 222): un principio teologico fondamentale per l'agire cristiano. Path, Città del Vaticano, v. 13, n. 2, p. 403-412, 2014. 
MERKS, K.-W. Steccati pieni di buchi? Sulla validità generale delle norme morali. In: GOERTZ, S.; WITTING, C. (A cura di). Amoris laetitia: un punto di svolta per la teologia morale? Cinisello Balsamo (Milano): San Paolo, 2017. p. 130-162.

O'COLLINS, G. The Joy of Love (Amoris Laetitia): the Papal Exhortation in Its Context. Theological Studies, USA, v. 77, n. 4, p. 905-921, 2016.

PASSOS, J. D. A alegria do amor: das sementes aos frutos. Roteiro de leitura da Exortação Apostólica Pós-sinodal Amoris Laetitia. São Paulo: Paulinas, 2016.

PASSOS, J. D. As fontes da Amoris Laetitia. São Paulo: Paulus, 2018.

PAULO VI, Papa. Humanae Vitae. Carta Encíclica sobre a regulação da natalidade. 9. ed. São Paulo: Paulinas, 2001.

PRINI, P. Lo scisma sommerso: il messaggio cristiano, la società moderna e la Chiesa cattolica. Roma: Garzanti, 1999.

SEIFERT, J. Amoris Laetitia: Joy, Sadness and Hopes. Aemaet: Wissenschaftliche Zeitschrift für Philosophie und Theologie, Deustschand, v. 5, n. 22, p. 160-249, 2016. Disponível em: https://www.aemaet.de/wp-content/uploads/2018/09/Amoris-LaetitiaJoy-Sadness-and-Hopes.pdf. Acesso em: 10 nov. 2020.

SALZMAN, T. A.; LAWLER, M. G. Sinalização do início de abertura na Igreja. Revista IHU On-Line, São Leopoldo, (18.04.2016). Disponível em: http://www. ihuonline.unisinos.br/artigo/6397-todd-a-salzman-e-michael-g-lawler-2. Acesso em: 22 nov. 2020.

SPADARO, A. Intervista a Papa Francesco. La Civiltà Cattolica, Italia, anno 164, n. 3918, p. 449-477, 2013.

SPADARO, A. Amoris Laetitia: Struttura e significato dell'Esortazione Apostolica Post-Sinodale di Papa Francesco. La Civiltà Cattolica, Itália, anno 167, n. 3980, p. 105-128, 2016a.

SPADARO, A. Conversazione com il Cardinale Schönborn sull' Amoris Laetitia. La Civiltà Cattolica, Italia, anno 167, n. 3986, p. 132-152, 2016 b.

WOJTYLA, K. Amore e responsabilità. Morale Sessuale e Vita Interpersonale. 4.ed. Genova: Marietti, 1983.

ZACHARIAS, R. Fundamentalismo ético-moral. Amoris Laetitia: um "não" radical à pretensão fundamentalista. In: MILLEN, M. I. de C.; ZACHARIAS, R. (Orgs.). Fundamentalismo: desafios à ética teológica. Aparecida: Santuário, 2017. p. 223-269.

Artigo submetido em 09.12.2020 e aprovado em 05.04.2021.

Ronaldo Zacharias tem Pós-Doutorado em Democracia e Direitos Humanos (Ius Gentium Conimbrigae - Universidade de Coimbra - Portugal), é Doutor em Teologia Moral (Weston Jesuit School of Theology - Cambridge - USA) e Secretário da Sociedade Brasileira de Teologia Moral (SBTM). Orcid.org/0000-0002-2895-6448. E-mail: sdbronaldo@uol.com.br

Endereço: Rua Dom Bosco, 100, Sta. Catarina 13466-327 Americana - SP - Brasil 